\title{
Definitive Management of Failure After Pyeloplasty
}

\author{
Ryan Swearingen, MD, Sapan Ambani, MD, Gary J. Faerber, MD, \\ David A. Bloom, MD, and J. Stuart Wolf Jr., MD
}

\begin{abstract}
Introduction: Failure after pyeloplasty is difficult to manage. We report our experience managing pyeloplasty failures.

Methods: We retrospectively reviewed the case log of a single surgeon, from August 1996 to August 2014, to identify all patients undergoing a surgical procedure after failed pyeloplasty. We excluded patients without follow-up exceeding 1 year from initial postpyeloplasty procedure. Failure was defined as a need for additional definitive intervention.

Results: Of 247 laparoscopic pyeloplasties, 68 endopyelotomies and 305 simple laparoscopic nephrectomies reviewed, 41 were performed after previous pyeloplasty and had sufficient follow-up. Laparoscopic nephrectomy was performed in nine patients. All three secondary laparoscopic pyeloplasties were successful. Of 29 secondary endopyelotomies, $10(34 \%)$ were successful. Of the 19 failures after secondary endopyelotomy, 12 patients had tertiary pyeloplasty (5 laparoscopic and 7 open surgical), 5 (26\%) underwent tertiary endopyelotomy, and $2(11 \%)$ required nephrectomy. Our overall endopyelotomy success rate was 38\% (13/34) vs 100\% (11/11) for secondary or tertiary pyeloplasty ( 4 patients lost to follow-up). Median time to failure was 5 months for endopyelotomy. Median follow-up for patients free from intervention was 40.2 months.

Conclusions: Secondary pyeloplasty (including both laparoscopic and open surgical approach) is more than twice as successful as endopyelotomy after failed pyeloplasty. Secondary pyeloplasty is an excellent alternative to endopyelotomy in select patients with failure after initial pyeloplasty.
\end{abstract}

\section{Introduction}

$\mathbf{I}^{\mathrm{N}}$ NTRODUCED IN 1993, LAPAROSCOPIC pyeloplasty is an accepted first-line approach to the patient with ureteropelvic junction (UPJ) obstruction. ${ }^{1}$ Laparoscopic pyeloplasty is associated with excellent success rates, $75 \%$ to $98 \% .^{2-7}$ Failure can and does occur, however, and the options for management include observation, stent placement, percutaneous nephrostomy, endopyelotomy, repeat pyeloplasty, or nephrectomy. ${ }^{8}$ These failures can sometimes be difficult to manage, and the decision, as to which procedure to perform, may not be clear.

Success rates of endopyelotomy for secondary UPJ obstruction have been reported as high as $70 \%$ to $87.5 \%{ }^{6,9}$ Endopyelotomy is a popular secondary procedure after failed pyeloplasty, as compared to repeat pyeloplasty, given reluctance to perform the latter due to perceived technical difficulty. However, a recent study by Vannahme and colleagues ${ }^{4}$ demonstrates greater success of pyeloplasty compared with endopyelotomy for secondary UPJ obstruction after failed pyeloplasty.

We reviewed our own case series to compare the outcomes of laparoscopic nephrectomy, laparoscopic pyeloplasty, and endopyelotomy as secondary operations after failed pyeloplasty, with the goal of further informing the management approach to these complicated patients.

\section{Materials and Methods}

\section{Data source and subjects}

We reviewed a prospectively maintained database that included a total of 620 endopyelotomies, laparoscopic pyeloplasties, and simple laparoscopic nephrectomies performed by a single surgeon between August 1996 and August 2014. We identified patients who underwent one of these surgical procedures as a result of a previously failed pyeloplasty. The initial pyeloplasties were not necessarily performed at our institution. Additionally, we included only those patients who had postprocedure follow-up of at least 1 year. Patients with a previously failed pyeloplasty who were managed with chronic ureteral stent exchanges were not included.

Data collected included patient demographics, operative details, laboratory data, and imaging studies, and the indications for reoperation. Nuclear medicine scans were obtained in only 13 patients before surgery $(44 \%)$, and $15(51 \%)$ after surgery (often different patients), so this parameter is

Department of Urology, University of Michigan, Ann Arbor, Michigan. 
not reported. Additionally, the degree of hydronephrosis was not consistently assessed on imaging, so this parameter was not reported.

Endopyelotomy was performed retrograde or antegrade. We employed a $2 \mathrm{~F}$ electrocautery probe, a $200 \mu \mathrm{m}$ Holmium: YAG laser fiber, cold hook knife or Acucise ${ }^{\circledR}$ device to incise posterolaterally. A $7 \mathrm{~F}$ to $10 \mathrm{~F}$ internal ureteral stent or externalized nephroureteral stent was left in place for 6 weeks. Imaging follow-up was with a nuclear medicine renal scan in most cases, but in some other modalities, intravenous urogram, CT scan, or nephrostogram, was used.

All laparoscopic pyeloplasties were performed transperitoneally, without robotic assistance. A closed suction drain was placed and removed before discharge, unless a urine leak was suspected. A 6F internal ureteral stent was left in place, and removed $\sim 3$ weeks after surgery. Follow-up imaging typically consisted of a nuclear medicine renal scan, however in some cases imaging consisted of an intravenous urogram (some patients early in the series) or nephrostogram (if a nephrostomy tube was left in place at the time of the pyeloplasty).

\section{Primary outcome}

Preoperative assessment included characterization of patient symptoms, physical examination, and review of imaging studies (including nuclear medicine diuretic renograms, CT scans, and ultrasounds) and laboratory results. Based on this clinical assessment, in a shared decision with the patient, it was decided if a salvage procedure was needed. The primary outcome was need for this secondary or tertiary procedure, which we defined as definitive intervention after endopyelotomy or pyeloplasty and was considered to be "failure." "Success" was the absence of failure, or in this case, no need for any further intervention. We decided upon this primary outcome, rather than one based upon radiographic criteria, as it is a "composite" outcome that factors in not only objective findings, but also the ultimate decision made by the patient-what is important in real life. Temporary drainage (ureteral stent or nephrostomy tube) with subsequent removal of the drain was not considered failure.

\section{Results}

Of 620 procedures reviewed, 44 were performed after previous pyeloplasty (Fig. 1). Of these patients, 3 were excluded due to follow-up of $<1$ year, leaving 41 patients for whom we performed a definitive secondary or tertiary procedure (laparoscopic pyeloplasty, endopyelotomy, or laparoscopic nephrectomy) after failed prior pyeloplasty. Of these 41 failed pyeloplasties, 15 had been performed with open surgery, 19 had been performed with standard laparoscopy, 2 had undergone robot-assisted laparoscopy, and for 3 patients the exact procedure could not be discerned from the medical record.

The initial management in 29 of the 41 patients was secondary endopyelotomy. Table 1 describes the demographics and operative details of these patients.

Tables 2 and 3 summarizes the outcomes after secondary endopyelotomy. Following secondary endopyelotomy, 10 patients $(34 \%)$ had long-term success, and did not have further intervention over a mean of 38 months follow-up (Table 2). Nineteen patients $(66 \%)$ ultimately required further intervention. Median time to failure was 5 months. There were no obvious factors associated with endopyelotomy outcome, however, having a previous open pyeloplasty was nearly statistically significant ( $p=0.051)$ (Table 3$)$. Of these 19 patients with failure of secondary endopyelotomy, 12 (63\%) underwent subsequent tertiary pyeloplasty (5 laparoscopic, 7 open). Of these 12 patients, 8 had follow-up for over 1 year and all were deemed successful. Of the 19 patients with failure of secondary endopyelotomy, 5 (26\%) underwent another endopyelotomy ("tertiary endopyelotomy"). Of these five patients, three $(60 \%)$ required no further surgical intervention for UPJ obstruction. This brought the overall
FIG. 1. Flowchart of operative success and failure in the management of pyeloplasty failures, based on operation.

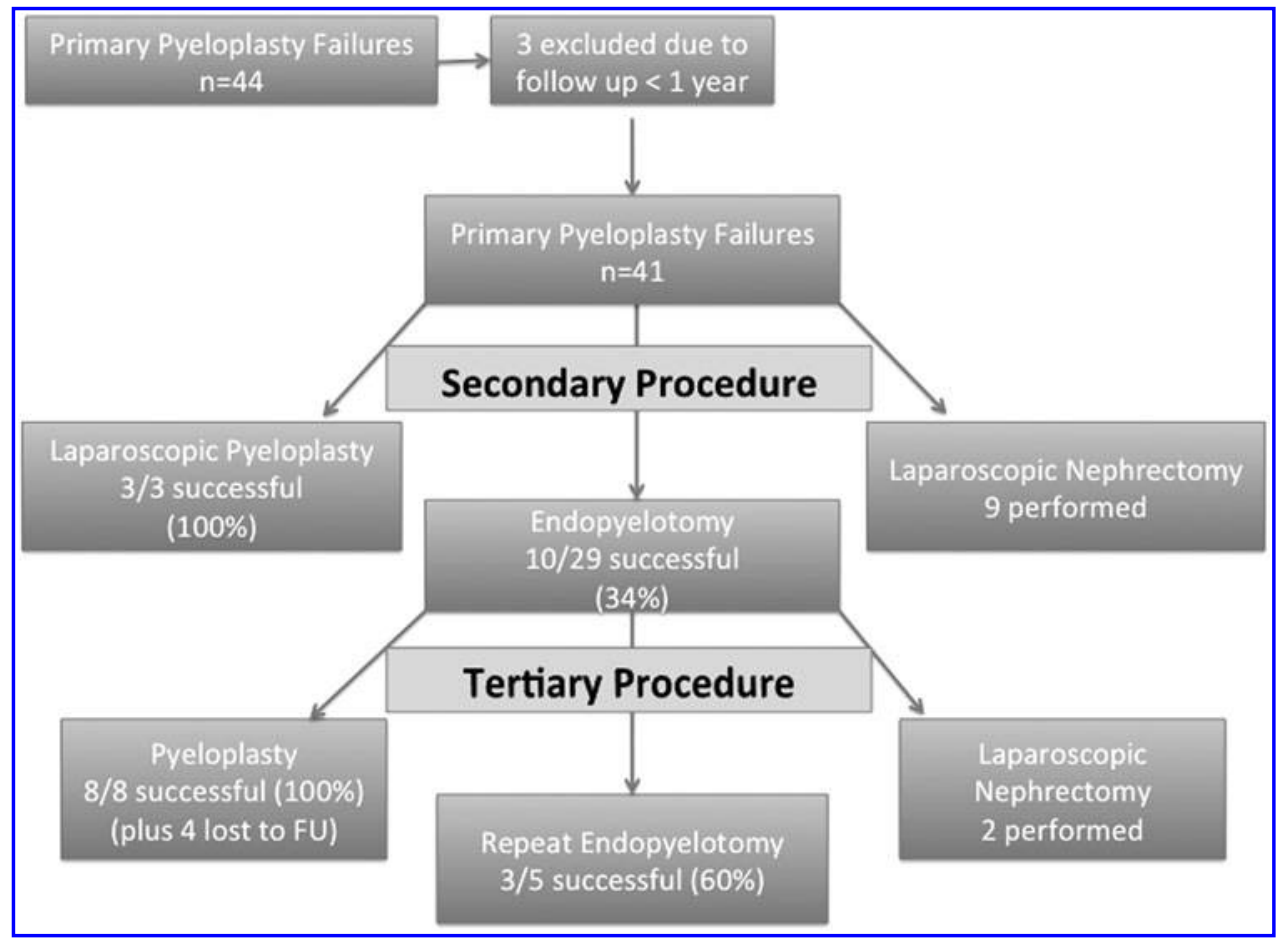


Table 1. Demographics/Operative Details: SECONDARY ENDOPYELOTOMIES

\begin{tabular}{|c|c|}
\hline $\begin{array}{l}N \\
\text { Gender } \\
\text { Male }\end{array}$ & 15 \\
\hline $\begin{array}{c}\text { Laterality } \\
\text { Right }\end{array}$ & 12 \\
\hline $\begin{array}{l}\text { Mean age, years (SD) } \\
\text { Mean BMI, } \mathrm{kg} / \mathrm{m}^{2}(\mathrm{SD})\end{array}$ & $\begin{array}{l}31.5(15.6) \\
25.7(3.18)\end{array}$ \\
\hline $\begin{array}{l}\text { Approach to previous pyeloplast } \\
\text { Open } \\
\text { Standard laparoscopy } \\
\text { Robot-assisted } \\
\text { Unknown }\end{array}$ & $\begin{array}{c}12 \\
13 \\
1 \\
3\end{array}$ \\
\hline Crossing vessel & 3 \\
\hline $\begin{array}{l}\text { Subsequent procedure } \\
\text { Pyeloplasty } \\
\text { Endopyelotomy } \\
\text { Nephrectomy }\end{array}$ & $\begin{array}{l}12 \\
5 \\
2\end{array}$ \\
\hline $\begin{array}{l}\text { Approach to endopyelotomy } \\
\text { Antegrade } \\
\text { Laser } \\
\text { Electrode/balloon dilation } \\
\text { Cold hook knife } \\
\text { Retrograde } \\
\text { Acucise } \\
\text { Electrode/balloon dilation } \\
\text { Laser } \\
\text { Unknown }\end{array}$ & $\begin{array}{c}4 \\
1 \\
1 \\
2 \\
25 \\
2 \\
1 \\
22 \\
1\end{array}$ \\
\hline $\begin{array}{l}\text { Mean EBL, mL (range) } \\
\text { Mean LOS, days (range) } \\
\text { Stent } \\
\text { PCN tube } \\
\text { Mean OR time, minutes (range) } \\
\text { ASA score (mean) }\end{array}$ & $\begin{array}{c}3(0-50) \\
0.3(0-2) \\
28 / 28 \\
6 \\
40.35(10-135) \\
1.7\end{array}$ \\
\hline $\begin{array}{l}\text { Complications (Clavien-Dindo } \\
\text { classification) } \\
1 \\
3 \mathrm{~b}\end{array}$ & $\begin{array}{l}1 \text { - postoperative bleed } \\
1 \text {-pyelonephritis needing } \\
\text { stent placement }\end{array}$ \\
\hline
\end{tabular}

ASA $=$ American Society of Anesthesiologists; BMI = body mass index; $\mathrm{EBL}=$ estimated blood loss; $\mathrm{LOS}=$ length of stay; $\mathrm{OR}=$ operating room; $\mathrm{PCN}=$ percutaneous nephrostomy; $\mathrm{SD}=$ standard deviation

success rate for endopyelotomy to $38 \%$ (13 of 34 procedures). Finally, two patients $(11 \%)$, based on symptoms as well as poorly functioning kidney by nuclear medicine scan, underwent a laparoscopic nephrectomy after failed secondary endopyelotomy.

Of the 12 patients undergoing a procedure other than endopyelotomy following the initial failed pyeloplasty, 3 un-

Table 2. Follow-Up and Management of SECONDARY ENDOPYELOTOMY FAILURE

\begin{tabular}{lr}
\hline Endopyelotomy failure, $N(\%)$ & $19(66)$ \\
Median overall follow-up, months (range) & $30(5-192)$ \\
Median time to failure, months (range) & $5(1-149)$ \\
Median follow-up for successes, & $38(12-169)$ \\
$\quad$ months (range) & \\
Subsequent procedure & $12(63)$ \\
Pyeloplasty, $N(\%)$ & $5(26)$ \\
Endopyelotomy, $N(\%)$ & $2(11)$ \\
Nephrectomy, $N(\%)$ & \\
\hline
\end{tabular}

Table 3. Factors Associated with Success vs FAilure in 29 Patients Undergoing SECONDARY ENDOPYELOTOMY

\begin{tabular}{|c|c|c|c|}
\hline Factors & $\begin{array}{l}\text { Success } \\
(\mathrm{N}=10)\end{array}$ & $\begin{array}{l}\text { Failure } \\
(\mathrm{N}=19)\end{array}$ & $\mathrm{p}$ \\
\hline \multicolumn{4}{|c|}{ Approach to prior pyeloplasty } \\
\hline Laparoscopic, $N(\%)$ & $7(70)$ & $6(32)$ & 0.22 \\
\hline Open surgical, $N(\%)$ & $2(20)$ & $10(53)$ & 0.051 \\
\hline Robotic, $N(\%)$ & $1(10)$ & 0 & NA \\
\hline \multicolumn{4}{|c|}{ Approach to endopyelotomy } \\
\hline Antegrade, $N(\%)$ & $1(10)$ & $3(16)$ & 1.0 \\
\hline Retrograde, $N(\%)^{\mathrm{a}}$ & $9(90)$ & $16(84)$ & 1.0 \\
\hline Crossing vessel, $N$ & 1 & 1 & 1.0 \\
\hline $\mathrm{BMI}, \mathrm{kg} / \mathrm{m}^{2}$ (mean) & 26.8 & 24.8 & 0.28 \\
\hline Age, years (mean) & 29.4 & 32.6 & 0.63 \\
\hline Male, $N(\%)$ & $5(50)$ & $10(53)$ & 1.0 \\
\hline Right side, $N(\%)$ & $3(30)$ & $9(47)$ & 0.45 \\
\hline
\end{tabular}

${ }^{\mathrm{a}}$ Among the 25 secondary retrograde endopyelotomies, the cutting modality used was Ho:YAG laser in 22, cold hook knife in 2, Acucise ${ }^{\circledR}$ in 2 , and electrocautery with dilation in 2 . The endopyelotomy was successful in 8,1,0, and 1 (total 10), respectively.

derwent a secondary pyeloplasty (all laparoscopic) and 9 underwent nephrectomy. Thus, a total of 11 patients underwent secondary/tertiary nephrectomy (Table 4).

All patients who underwent a secondary pyeloplasty had success (no further intervention) with a median follow-up of 20 months (Table 5). When taking into account the additional 8 tertiary pyeloplasties with follow-up of $>1$ year, there were 11 total secondary and tertiary pyeloplasties, all of which were successful, with a median follow-up of 30 months. Of the 11 pyeloplasties with sufficient follow-up included in our study, 6 were performed using a dismembered technique and in 5 a nondismembered technique (Y-V pyeloplasty) was used. When all pyeloplasties were included, including those who followed up for $<1$ year, median follow-up was 20 months (Table 5).

Complications are listed in Table 6. Complications of the pyeloplasties included Clavien 2 complications in one open pyeloplasty patient and in two laparoscopic pyeloplasty patients. Complications included postoperative fever/and

Table 4. Demographics/Operative Details FOR SECONDARY/TERTIARY LAPAROSCOPIC NePHRECTOMY

\section{Summary table}

$N$ 11

Mean age, years (SD)

$40(12)$

Laterality Right

7

Gender

Male

2

BMI, $\mathrm{kg} / \mathrm{m}^{2}$ (SD)

Median follow-up, months (range) $1(0-192)$

Type of previous pyeloplasty

Laparoscopic Open

Complications
6

5

$\mathrm{CII}-$ sepsis requiring IV antibiotics (1) 
Table 5. Demographics/Operative Details FOR SECONDARY/TERTIARY Pyeloplasties After Failed Primary Pyeloplasty

\begin{tabular}{|c|c|c|}
\hline & $\begin{array}{c}\text { Secondary } \\
\text { pyeloplasties }\end{array}$ & $\begin{array}{c}\text { Tertiary } \\
\text { pyeloplasties }\end{array}$ \\
\hline$N$ & 3 & 12 \\
\hline Mean age, years (SD) & $51(8)$ & $29(14)$ \\
\hline $\begin{array}{l}\text { Laterality } \\
\text { Right }\end{array}$ & 1 & 3 \\
\hline $\begin{array}{r}\text { Gender } \\
\text { Male }\end{array}$ & 0 & 8 \\
\hline BMI, kg/m² (SD) & $28.0(9.8)$ & $24.9(3.2)$ \\
\hline $\begin{array}{l}\text { Type of previous pyelopl } \\
\text { Robotic } \\
\text { NA } \\
\text { Open } \\
\text { Laparoscopic }\end{array}$ & $\begin{array}{l}1 \\
2 \\
0 \\
0\end{array}$ & $\begin{array}{l}0 \\
1 \\
7 \\
4\end{array}$ \\
\hline $\begin{array}{l}\text { Mean LOS, days (range) } \\
\text { Mean EBL, mL (range) } \\
\text { Mean OR time, }\end{array}$ & $\begin{array}{c}1.3(1-2) \\
83(25-175) \\
199(123-315)\end{array}$ & $\begin{array}{c}3(1-7) \\
145(25-600) \\
209(135-270)\end{array}$ \\
\hline $\begin{array}{l}\text { minutes (range) } \\
\text { Median follow-up, } \\
\text { months (range) }\end{array}$ & $20(15-21)$ & $20(1-75)$ \\
\hline Success & $3 / 3$ & $12 / 12$ \\
\hline Complications & None & $\begin{array}{l}\text { CII-fever/ } \\
\text { suspected } \\
\text { UTI, treated } \\
\text { with abx (2); } \\
\text { CII-Cdiff/ } \\
\text { UTI }\end{array}$ \\
\hline
\end{tabular}

$\mathrm{UTI}=$ urinary tract infection.

suspected or documented urinary tract infection (UTI) requiring antibiotics (two patients). The third patient had a prolonged urine leak (Clavien 1) and a febrile UTI and Clostridium difficile infection requiring treatment with antibiotics (Clavien 2). Complications in the endopyelotomy patients included one patient who developed pyelonephritis and required intraoperative stent placement (Clavien 3b). A second patient had a postoperative hemorrhage that did not require transfusion (Clavien 1). Complications associated with nephrectomy included one patient, who developed fever and concern for sepsis, requiring IV antibiotics (Clavien 2).

\section{Discussion}

Our overall success rate for secondary or tertiary pyeloplasty in our series was $100 \%$, whereas the success rate was
$34 \%$ for secondary/tertiary endopyelotomy. Our secondary pyeloplasty success rate is slighter better than that reported in the literature (83\%-95\%), ${ }^{10,11}$ but our salvage endopyelotomy success rate is lower than that reported even in recent studies. ${ }^{4}$ The median failure time for endopyelotomies was about 5 months, and with an overall follow-up of 38 months for successful endopyelotomies we are confident that we have captured most endopyelotomy failures. We have a similarly long follow-up of a median 19 months after the secondary and tertiary pyeloplasties. These data suggest long-term sustainability of the laparoscopic pyeloplasty operation.

It has previously been our practice, as well as commonly reported in the literature, to perform an endopyelotomy after failure of a pyeloplasty. Jabbour and colleagues ${ }^{9}$ evaluated success rates for secondary endopyelotomy in 1998, and success rates were reported as high as $87.5 \%$ over 88 months. Given the minimally invasive nature of the procedure, this would seem to be a good option. However, more recent data seem to indicate that these results are not reproducible. $\mathrm{Ng}$ and coworkers $^{12}$ describe a lower success rate of $59 \%$ for secondary endopyelotomy, although it is noted that cases in this study were performed after both previous endopyelotomy and pyeloplasty failures. Park and colleagues ${ }^{7}$ note a $70 \%$ success rate over a 47 month follow-up period. Patel and colleagues ${ }^{13}$ describe an $84 \%$ success rate in antegrade secondary endopyelotomies. It is unclear as to why patients in these studies had higher success rates with endopyelotomy when compared to our group.

With regard to secondary laparoscopic pyeloplasties, recent data seem to mirror ours in terms of excellent success rates. Shadpour and coworkers ${ }^{14}$ had similar results in terms of outcomes in revision laparoscopic pyeloplasties, with 10 of 11 successful cases in failed previous open repair. As noted previously, Sundaram and colleagues ${ }^{11}$ also had success rates of 83\% for salvage laparoscopic pyeloplasty for secondary UPJ obstruction. Most recently, Vannahme and colleagues ${ }^{4}$ noted an $87.5 \%$ success rate for secondary UPJ obstruction. Their case series is notable for 41 patients with failed initial pyeloplasty (similar to our series), and 17 patients with previous failed endopyelotomy. Their final calculations took into account success rates of pyeloplasty after both procedures, although on review, it appears they also had $100 \%$ success in patients who underwent a laparoscopic pyeloplasty after failed primary pyeloplasty (10/10 patients, 11 th patient lost to follow-up). ${ }^{4}$ They also note 22 of the initial failed primary pyeloplasties were done open. In a 2015 study, Abraham and colleagues ${ }^{15}$ showed results similar to our case series, with 15 of 16 patients $(93 \%)$ who successfully underwent laparoscopic pyeloplasty as initial intervention for failed previous pyeloplasty. Follow-up was over a 30-month period. They did note

Table 6. Outcomes After Failed Primary Pyeloplasty

\begin{tabular}{|c|c|c|c|c|}
\hline & $\begin{array}{c}\text { Secondary } \\
\text { endopyelotomy }\end{array}$ & $\begin{array}{c}\text { Secondary } \\
\text { pyeloplasty }\end{array}$ & $\begin{array}{c}\text { Tertiary } \\
\text { pyeloplasty }\end{array}$ & $\begin{array}{c}\text { Secondary/ } \\
\text { tertiary nephrectomy }\end{array}$ \\
\hline $\begin{array}{l}\text { Median follow-up, } \\
\text { months (range) }\end{array}$ & $30(5-192)$ & $20(15-21)$ & $20(1-75)$ & $1(0-192)$ \\
\hline Failures, $N(\%)$ & $19(66)$ & $0(0)$ & $0(0)$ & NA \\
\hline Complications & $\begin{array}{l}\text { CI-post operative } \\
\text { bleed (1); CI- } \\
\text { pyelonephritis needing } \\
\text { stent placement (1) }\end{array}$ & None & $\begin{array}{l}\text { CII—fever/suspected UTI, } \\
\text { treated with abx (2); } \\
\text { CII-Cdiff/UTI }\end{array}$ & $\begin{array}{l}\mathrm{CII}-\text { sepsis requiring IV } \\
\text { antibiotics (1) }\end{array}$ \\
\hline
\end{tabular}


operative times were longer for revision pyeloplasties compared with primary procedures (145 minutes $v s 191$ minutes).

Limitations of our study include a small patient population, with a single surgeon performing the revision laparoscopic surgeries at a single institution. Secondary UPJ obstruction is not common, and even over the 18-year period we reviewed, we were limited in our number of subjects who required such intervention. While we did note success in all patients for whom a secondary laparoscopic pyeloplasty was performed, the series is small; with only 11 patients reviewed, one failure would decrease the success rate significantly.

Laparoscopic surgery also requires extensive training and, therefore, these results may not be expected in the hands of surgeons who are less experienced with laparoscopy. We did not base success and failure upon objective imaging criteria. Although it could be argued that our clinical endpoint could be subject to bias, we feel that the decision to perform a repeat surgery is an endpoint that is most applicable to the real world. Finally, since we identified cases by procedure rather than by diagnosis, patients referred to the senior author who were referred to another provider for open surgical reconstruction were not included.

We were not able to determine any factors associated with the outcome of endopyelotomy, although our data are incomplete in this regard. Previous studies have suggested that poor renal function, longer stricture length, significant hydronephrosis, and etiology of the stricture contribute to failure of an endopyelotomy. ${ }^{7,16}$ This may have been a contributory factor to our low success rate for endopyelotomy as compared to our pyeloplasty group. Selection bias may have also played a role.

Our results suggest that for initial management of a pyeloplasty failure, if technically feasible, one should consider a pyeloplasty as an alternative to endopyelotomy given the notably higher success rate. Situations where our results may not be applicable include an intrarenal pelvis, as well as a long ureteral stricture with a small pelvis. In this situation, alternative approaches to revision would be the preferred option.

\section{Conclusion}

In recent decades, endopyelotomy has been the most commonly reported secondary procedure after failed pyeloplasty. Our current study, as well as other recent published data, indicate that secondary pyeloplasty has a higher success rate than endopyelotomy in select patient given surgeon expertise. Secondary laparoscopic pyeloplasty should be considered an excellent alternative when technically possible.

\section{Author Disclosure Statement}

No competing financial interests exist.

\section{References}

1. Schuessler WW, Grune MT, Tecuanhuey LV, et al. Laparoscopic dismembered pyeloplasty. J Urol 1993;150: 1795-1799.

2. Lucas SM, Sundaram CP, Wolf JS, et al. Factors that impact the outcome of minimally invasive pyeloplasty: Results of the Multi-institutional Laparoscopic and Robotic Pyeloplasty Collaborative Group. J Urol 2012;187:522-527.

3. Madi R, Roberts WW, Wolf JS, Jr. Late failures after laparoscopic pyeloplasty. Urology 2008;71:677-680.

4. Vannahme M, Mathur S, Davenport K, et al. The management of secondary pelvi-ureteric junction obstruction A comparison of pyeloplasty and endopyelotomy. BJU Int 2013;113:108-112.

5. Davenport K, Minervini A, Timoney AG, et al. Our experience with retroperitoneal and transperitoneal laparoscopic pyeloplasty for pelvi-ureteric junction obstruction. Eur Urol 2005;48:973-977.

6. Varkarakis IM, Bhayani SB, Allaf ME, et al. Management of secondary ureteropelvic junction obstruction after failed primary laparoscopic pyeloplasty. J Urol 2004;172:180-182.

7. Park J, Kim WS, Hong B, et al. Long-term outcome of secondary endopyelotomy after failed primary intervention for ureteropelvic junction obstruction. Int J Urol 2008;15: 490-494.

8. Tan H-J, Ye Z, Roberts WW, et al. Failure after laparoscopic pyeloplasty: Prevention and management. J Endourol 2011; 25:1457-1462.

9. Jabbour ME, Goldfischer ER, Klima WJ, et al. Endopyelotomy after failed pyeloplasty: The long-term results. J Urol 1998;160:690-692; discussion 692-693.

10. Inagaki T, Rha KH, Ong AM, et al. Laparoscopic pyeloplasty: Current status. BJU Int 2005;95 Suppl 2:102-105.

11. Sundaram CP, Grubb RL III, Rehman J, et al. Laparoscopic pyeloplasty for secondary ureteropelvic junction obstruction. J Urol 2003;169:2037-2040.

12. $\mathrm{Ng} \mathrm{CS}$, Yost AJ, Streem SB. Management of failed primary intervention for ureteropelvic junction obstruction: 12Year, single-center experience. Urology 2003;61:291-296.

13. Patel T, Kellner CP, Katsumi H, et al. Efficacy of endopyelotomy in patients with secondary ureteropelvic junction obstruction. J Endourol 2011;25:587-591.

14. Shadpour P, Haghighi R, Maghsoudi R, et al. Laparoscopic redo pyeloplasty after failed open surgery. Urol J 2011; 8:31-37.

15. Abraham GP, Siddaiah AT, Ramaswami K, et al. Laparoscopic management of recurrent ureteropelvic junction obstruction following pyeloplasty. Urol Ann 2015;7:183-187.

16. Gupta M, Tuncay OL, Smith AD. Open surgical exploration after failed endopyelotomy: A 12-year perspective. J Urol 1997;157:1613-1618; discussion 1618-1619.

Address correspondence to: J. Stuart Wolf Jr., MD Department of Urology University of Michigan

1500 E Medical Center Drive Ann Arbor, MI 48109-5330

E-mail: wolfs@med.umich.edu

\begin{tabular}{|c|}
\hline Abbreviations Used \\
$\mathrm{CT}=$ computed tomography \\
$\mathrm{UPJ}=$ ureteropelvic junction \\
$\mathrm{UTI}=$ urinary tract infection
\end{tabular}

